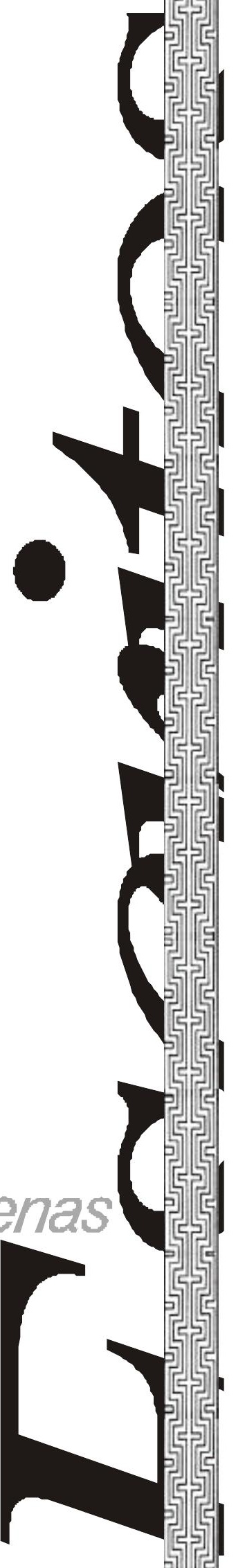





\title{
Escritura en castellano: un trauma más allá de la escuela
}

\author{
Gloria Huanca Callisaya
}

El presente trabajo es parte de la reflexión realizada respecto a las formas de aprendizaje oral y escrito de una segunda lengua, que en mi caso es "el castellano". En ella se describen los contenidos y estrategias abordadas - durante la primaria y secundaria- para tales situaciones.

En una primera parte describo mi forma de aprendizaje de la lengua oral del castellano y en una segunda parte la forma del aprendizaje escrito del castellano, todo esto, desde los procesos de enseñanza escolarizada de ese entonces y desde las formas de enseñanza en mi familia y comunidad. En la forma de enseñanza describo los contenidos y las finalidades del aprendizaje del castellano. Finalmente, concluyo reflexionando sobre el proceso de aprendizaje escrito de la lengua castellana y describiendo algo de mí.

\section{Aprendizaje oral del castellano}

El aprendizaje oral de la lengua castellana lo tengo desde el nacimiento, dice mi madre. Mis padres ${ }^{1}$, por el hecho de haber vivido en otras ciudades como Oruro, Cochabamba y Santa Cruz y además de haber compartido una buena parte de su juventud con personas de hablaba quechua y algunos misioneros de habla castellana - que en el caso de mi padre resultó ser pastor evangélico - tenían conocimiento sobre la lengua castellana y otras lenguas como el quechua y el aymara. Según mi madre el aymara lo aprendí también desde la cuna porque ella y las jóvenes que le ayudaban a cuidarme (Lidia Choque, Filomena y Sebastiana) me hablaban en aymara. El entorno familiar y comunal que nos rodeaba era aymara hablante y en caso de mis abuelitas, de ambos progenitores, eran monolingües aymaras.

Professora aymara, mestre em Desenvolvimento pela Universidad Católica Boliviana San Pablo e mestranda em Educação Intercultural Bilingüe pelo Programa de Formación en Educación Intercultural Bilingüe para los Países Andinos (PRO EIB-Andes) e Universidad Mayor de San

Simón (UMSS). ghuanca@proeibandes.org 
Mi madre solía contar también historias referidas al aprendizaje de una segunda lengua (el aymara) de mi hermano mayor, que nació en Santa Cruz (kilómetro 5 carreta antigua a Cbba). Cuando retornaron a Villa Remedios era un niño de cuatro años, monolingüe castellano hablante; esta condición no le permitía entender la conversación en aymara que mis padres entablaban con los familiares de mi padre; escuchando esas conversaciones, mi hermano se reía diciendo "la abuelita tan tin tan nomás habla". Quizá fue esa la razón por la que mi madre a mi segundo hermano y a mí nos enseñó a hablar el aymara con mayor importancia.

Durante la década de los setenta y ochenta fue cuando desde la escuela Jhon F. Kennedy de Villa remedios-Ingavi tuve la oportunidad de aprender la escritura del castellano. El aprendizaje escrito de esta lengua se desarrolló a lo largo de la formación escolarizada, incluso la formación del pre y post grado. En esos años la política lingüística de carácter estatal era "castellanizar al indio", integrar a la vida civilizatoria, entendiendo como civilización saber escribir el castellano y conocer las normas de urbanidad.

Durante esos años recuerdo que hasta mi padre era el opositor al uso oral de la lengua aymara en los espacios de socialización familiar. Mi madre a pesar de ser enfermera siempre demostró - hasta hoy - ese apego fiel al uso oral de la lengua aymara y junto a ella a la cultura. Era usado el aymara - con mi madre - para saludarnos, platicar sobre el cuidado de los animales ${ }^{2}$ las tareas escolares, las normas de vida como: la limpieza de las prendas, los alimentos, el saludo con los mayores; nos relataba también la historia familiar referido a sus papás y algunos de sus tíos que vivían en Santa Cruz, los familiares de mi papá, los casos de enfermedad, las historias de los pacientes que había atendido en la Posta Sanitaria. Mi padre al escuchar el uso oral de esta lengua de manera constante en mi madre la regañaba diciendo "aymara nomás estás hablando ¿hasta cuándo? En mi escuela hasta mis alumnos ya saben hablar bien el castellano y voz aymara nomás les estas enseñando". Estos regaños al parecer le entraban por un iodo y le salían por el otro a mi madre y como mi padre por su formación de profesor rural trabajaba lejos - por esos años - se quedaba por poco tiempo en mi casa, permitiendo así que nosotros sigamos con la lengua vernácula, tanto así que mi segundo hermanos hablaba tan lindo el aymara que en mi pueblo lo apodaron "el aymarista". El uso constante de esta lengua no quería decir que nosotros no supiéramos hablar el castellano, para esa época y la forma en cómo se usaba el castellano creo que éramos los que hablamos el castellano.

Durante esos años en mi pueblo se usaba la lengua nativa en la mayoría de los espacios comunicativos, como comprar pan u otros 
productos, diciendo tíyu t'ant'a aljita 'tío vendeme pan'; era también usado en la chacra, la crianza de animales, los tejidos, las fiestas sociales hasta las atenciones médicas realizadas en la Posta Sanitaria. El castellano era usado en los ámbitos educativos (enseñanza y aprendizaje de la escuela y el colegio), el día de feria (los días miércoles) porque desde la ciudad de La Paz llegaban las y los vendedoras de prendas de vestir $u$ otros productos como alcohol, medicamentos, los galenos (dentistas y médicos cirujanos), los colectiveros y sus ayudantes, los p'axpakunaka 'mamones' (que bajaban dinero por apuestas en cartas) y otras personas que usaban en algunos casos sólo el castellano. Los otros días lo que normalmente se usaba - en el hablar de los mayores, jóvenes y niños - era la lengua aymara. Durante esos años apenas los pobladores de Villa Remedios estaban en una etapa de adquisición de la lengua castellana, más a partir de la feria, porque este les permitía el contacto con personas que usaban la lengua castellana. Durante ese proceso de aprendizaje era normal escuchar palabras mezcladas entre el castellano y el aymara como: el qhiti en el jawira a chhaqtado siempre 'el qhiti en el rio se ha perdido siempre'; mi mallq'a me duele 'mi garganta me duele'. Desde esos procesos de adquisición de una segunda lengua hoy se ve casi todo lo contrario. Todos los jóvenes hablan la lengua castellana y de manera fluida, en cuanto al aymara, entienden pero ya no lo usan como lengua de socialización primaria.

\section{Aprendizaje escrito del castellano}

En el marco de las políticas asimilacionistas estatales, el docente cumplía con ese rol "principal" desde la enseñanza de la escritura del castellano. El hecho de ser "profesor" le daba un papel de autoridad, que la ejercía no sólo sobre los niños, sino también sobre los aspectos institucionales y su entorno humano como ser los representantes de la asociación de padres de familia y padres de familia a quienes también les podía regañar o tratar mal por alguna conducta no aceptada (por el docente) que manifestaba el niño o la niña en el ámbito escolar.

Poco o casi nada importaba el aprendizaje de conocimientos por parte de los niños y niñas. Tampoco se entendía el aprendizaje de la escritura como medio de comunicación o construcción de conocimientos, menos como un instrumento que permite establecer relaciones de poder.

Durante la implementación de estos modelos asimilacionista y homogeneizadores por medio del castellano el profesor tenía el poder epistemológico asignado desde el estado, su formación como maestro y 
como reconocimiento desde los padres de familia. Los profesores a rótulo de enseñanza y ese poder epistémico podían agredir psicológica y físicamente, llegando incluso a golpear a los pequeños estudiantes cuantas veces considerasen importante y necesario para su instrucción.

Durante esas épocas vivíamos - los niños y niñas - en una pedagogía del miedo y el terror. El profesor era como un monstruo malo que nos gritaba, se enfurecía, golpeaba, castigaba, jaloneaba, insultaba hasta podía votarnos del curso. Le teníamos miedo a que nos mire, nos pregunte, nos saque al pizarrón y al mínimo error nos golpee. Cuando no hacíamos las tareas éramos también victimas de gritos, insultos, apodos como "indios", "flojos", "burros". Uno de los castigos horribles registrados en mi mente como una cinta de película es cómo mi profesor de cuarto $\left(q^{\prime} u c h a l{ }^{3}\right.$, grandulón y corpulento) les castigaba a mis compañeros de curso; entre ellos mi segundo hermano ${ }^{4}$ (que no pudo resolver cierto ejercicio matemático) fue castigado al chancho ${ }^{5}$. Este tipo de castigo era por tiempos prolongados entre media hora, una hora o toda la clase. Era demasiado tiempo para que los niños se sostengan sobre sus manitos. De hecho no podían aguantar el peso del cuerpo, al poco rato caían al piso apoyándose en sus pechos y rostros. Mientras tanto, el profesor hacia su clase como si nada hubiese pasado en el curso. Yo observaba el rostro de mi hermano que ya estaba lleno de lágrimas, al igual que de los otros niños, con el moquito untado en la cara y sin poder limpiarse. Tanto sería el odio del profesor hacia los indígenas que no contento con ese castigo se atrevía a pisarlos y caminar por encima de sus cuerpitos con lo grandote que era. Asistir a clases era como asistir a un centro de torturas sicológicas y físicas. De seguro este fue la razón para que a mi hermano no le haya agradado la escuela y no haya concluido con su bachillerato a tiempo.

En algunos cursos y con docentes de ese tipo así era la enseñanza de los contenidos centrados en la escritura y la aritmética del castellano.

En la vida de estudiante universitaria con mucha razón mi docente de socioantropología solía decirnos:

El niño es sometido a la escuela por sus padres y su maestro/a. Desde su casa es obligado a asistir para no ser igual que su padre. En la escuela es castigado para no ser igual que su padre. Además que se encuentra en la difícil tarea de elegir uno de los dos mundos puestos en la balanza (su propia cultura y la cultura occidental). Cuando elige una, desecha la otra. Generalmente se ha desechado lo propio de su entorno y elegido el mundo del blanco para desde ese momento avergonzarse de su gente hasta maldecirse a sí mismo. (Waldo Jordán. 2001. UCB, La Paz) 
La escuela de ese entonces, se desarrollaba bajo concepciones totalmente contrarias al contexto donde nos encontrábamos, haciendo que los niños y niñas seamos el sándwich entre los padres y los docentes, y por supuesto, soportando todo tipo de malos tratos. Por ello, el aprendizaje escrito del castellano es un trauma que se arrastra más allá de la escuela.

Leyendo las palabras de Ticona (2005), encuentro en esas acciones del profesor la realización del concepto de la otredad. El concepto del "otro", llegó a América con Cristóbal Colón en el año 1492, imaginario defectuoso del "otro" (indio). Este concepto asociado a la idea de civilización, para Colón, dice el autor, constituía una forma de vida que no tenía el carácter histórico ni cambiante, sino era lo natural y lo racional, organizados a partir de los reyes, las leyes y las ciudades. Bajo este marco de pensamiento, Colón pensó que al "otro" le faltaba uno de los elementos claves para su definición concreta: la verdad cristiana, esta carencia hacía notar ser inferior al europeo.

El rey era quien mantenía el orden social y defendía a los indefensos. Mientras que las leyes partían de la concepción de que el hombre era pecador $\mathrm{y}$, por tanto, sujeto a las tentaciones de la vida; esta reacción natural-racional se tenía que controlar mediante las leyes. Finalmente la ciudad estaba relacionada con la formación espacial urbana, que se definía con relación al espacio rural. El espacio urbano era percibido como área socializada y el rural como aquello no socializado. (Frank, 1993, p.31 en lecturas para la descolonización de Esteban Ticona, 2005)

Este imaginario del "otro" inferior al europeo construido por Colón, según Ticona apoyado en Frank, fue transformado por Vespucci y cierta capa de intelectuales, quienes construyeron el estereotipo del indio salvaje no civilizado de la siguiente manera:

Los indios no tenían bienes ni territorio, no tenían ley contra el incesto, no sabían contar los días, meses y años, eran bélicos y crueles, etc.; lo que completo la imagen del "otro" (indio) americano" (Ibid).

Vespucci, sin eliminar las monstruosidades de Colón, creo una imagen totalizadora del indio, caracterizando como un agente opositor al europeo; si bien ya no tenía la cabeza de perro, o la cola; hizo aparecer la idea del "otro" como antropófago, que comían carne humana, por tanto indios defectuosos.

El mundo occidental siempre tuvo arraigo por sus leyes, preocupación permanente por los reyes católicos, escribanos, colonizadores, y la escuela fue un ente que operacionalizó todo ese pensamiento. El eurocentrismo tuvo su resplandor desde esos momentos, cegándose ante otras formas de vida, de aprender, de saberes, valores, tecnología, espiritualidad y otras concepciones del mundo que no solo se basan en el monoteísmo. 
Volviendo a mi relato, mi profesor de esos años tenía pues bien clara la imagen del "otro defectuoso", sin leyes y derechos a nada.

\section{Los contenidos}

Entre los contenidos de aprendizaje del castellano escrito se priorizaban las vocales y las consonantes del alfabeto. De hecho, el texto de apoyo utilizado por ese entonces era "Alma de niño". El proceso de enseñanza giraba en torno a la apropiación de las letras del castellano. Se priorizaba la escritura del castellano antes que la pronunciación o la lectura. Para escribir se iniciaba por el dibujo de las letras (grafías del alfabeto) y luego su pronunciación.

En este proceso no parecía ser importante ni siquiera aprender bien la gramática de la lengua castellana, sino el "codificar y decodificar" (leer textos escritos y copiar textos sin reflexionar sobre ellos).

El primer contenido de aprendizaje estaba casi siempre relacionado a las vocales como / a/ a través de la palabra "ala", / e/ con "enano", /i/ con "iglesia", /o/ con "oso" y / u/ con "uva". Posteriormente se pasaba a complementar vocales y consonantes en sílabas como: ma, me, mi, mo, mu, conocido como el método silábico que va desde las partes hacia el todo. En este sentido, los contenidos se complejizaban de vocales, sílabas, palabras a oraciones. Sin embargo jamás se explicaba el significado de muchas palabras totalmente desconocidas para nosotros, como ser: cine, jirafa, etc.

En la formación secundaria los contenidos giraban, por un lado, en torno a la gramática del castellano. Esta enseñanza se centraba en el conocimiento de las oraciones y los componentes de la misma; por otro lado, los géneros literarios y la lectura de obras literarias. El objetivo de las lecturas estaba más orientado a desarrollar la agilidad en la lectura, la pronunciación de las palabras, el respetar los signos de puntuación antes que la comprensión o la reflexión sobre los textos leídos. En la práctica no se lograba ni uno ni el otro.

En resumen nunca me enseñaron a producir textos. La máxima producción fue escribir una carta familiar, ni siquiera un cuento, una descripción de un día en la chacra. Entre los puntos de vista, respecto al aprendizaje de contenidos, los docentes nos decían que "como son campesinos solo necesitan algunas cosas para defenderse y en matemática aprender las cuatro operaciones para vender sus productos". Nunca hubo en sus mentes que un día como hoy llegaríamos lejos, a pesar de todo. 
Las clases se centraban siempre en la escritura de dictados, escribir lecciones de contenidos occidentales (como cívica, química, física, matemática, literatura, filosofía) en las carpetas individuales. Analizando ahora diría que había aprendido a codificar y decodificar. A pesar de desarrollar la clase con exposiciones sobre algunos temas de historia, ciencias naturales y otros, estos se remitían a la simple repetición de los textos escritos. De hecho, los estudiantes éramos mejores mientras más similar al texto dictado o leído era nuestro aprendizaje. Entonces estábamos en una pedagogía de la "repetición" y reproducción de conocimientos occidentales.

Como todo estudiante yo, para no recibir castigos, debía cumplir con todas las tareas que me eran encomendadas por mis profesores. Mientras un estudiante más sumiso, humilde y obediente era, pasaba a ser considerado un buen estudiante. Como se había implantado el respeto al maestro por "miedo", era muy impotente a poder revelarme. Las palabras de los docentes eran palabras indiscutibles, aunque se equivocasen. Con esta forma de enseñanza se imponía la pedagogía del "cumplimiento". Se hacía todo por cumplir y porque ese cumplimiento se transformaba en notas de aprobación y acreditación de los años de estudio.

En este enfoque tradicional de transmisión de conocimientos a mis profesores no les importaba si los niños sabíamos expresarnos en castellano, si entendíamos lo que leíamos y mucho menos si podíamos producir textos, aunque sean cortos. Lo importante era escribir los dictados, leer algún párrafo y memorizar, incluyendo las pausas marcadas por signos de puntuación.

La exposición a esta institución llamada "escuela" y cuarto de "torturas sicológicas y físicas", hizo que muchas jóvenes -mujeresabandonaran la escuela o el colegio a lo largo de los años. De mi pueblo, en 1989, era la única mujer que se graduaba y en el curso éramos solo dos mujeres, la otra era de Caluyo, una comunidad aledaña a Villa Remedios. Por esos años el abandono escolar era alto, incluso en los varones. De mi pueblo solían graduarse de tres a cinco jóvenes, el resto eran de las comunidades que circundaban. Aun así, el número de graduados llegaba de 13 hasta 27 estudiantes, cantidad considerada como la promoción más numerosa en 1983, claro que ahora es diferente, la mayoría de los jóvenes de mi pueblo son bachilleres y el número de graduados por género aumentó sustancialmente. Ahora, todos estudian. Será la habilidad para el uso del castellano. 


\section{Las finalidades del aprendizaje escrito del castellano}

Las principales finalidades de la educación eran aprender el castellano: a) a partir de la escritura de las vocales y copia de libros, b) hablar el castellano a partir de la lectura de textos y la repetición de sílabas, palabras y oraciones. Durante estos años era importante integrarse al estado nación como ciudadano por medio del castellano.

Mientras tanto la lengua aymara y la cultura eran totalmente descalificadas y consideradas retrógradas, problemáticas para el aprendizaje del castellano. En esas épocas era vergonzoso decir soy aymara, campesino o indígena, todos querían ser iguales al blanco, en su ropa y sus formas de vida urbana, en su lenguaje. A comparación, eran mal vistas las ropas de las mujeres y hombres indígenas (manta, pollera, poncho y otras prendas) incluso la de autoridades originarias.

Desde esa época a la actualidad ha cambiado mucho, e incluso se habla con más resonancia de lo indígena antes que lo campesino. Ahora, es un orgullo decir nuestra identidad porque el contexto político así lo permite y los movimientos sociales lucharon por esos cambios.

Pese a las políticas asimilacionistas, la exposición a instituciones como la escuela y el colegio, no se han podido borrar (en mí y en una mayoría de los aymaras) todos los conocimientos y el aprendizaje de la lengua aymara. Hoy, al igual que ayer, sigo usando la lengua vernácula con mi madre para hablar de las mismas temáticas que siempre hablábamos. Respecto a mi padre, ya no piensa igual que ayer, ahora comprendió la importante tarea de la enseñanza de la lengua aymara de mi madre.

Respecto al aprendizaje de la escritura del castellano, aprendí muy poco o casi nada en la formación escolarizada, por una enseñanza que se limitaba a la simple codificación y decodificación; nunca me enseñaron a producir textos, ni con qué tipo de verbos se escribe cada texto. Una experiencia muy grande me toco vivir mientras escribía los "Lineamientos políticos de EIB para la Educación Alternativa" durante mi experiencia laboral en el Ministerio de Educación, preguntaba con qué tipo de verbos y en que tiempos verbales se escribe los lineamientos políticos; pero, al parecer no solo era yo la que desconocía, por lo que aprendimos en grupo.

El realizar cursos de maestra en la normal me ayudó a comprender la importancia de la lengua escrita como sistema de comunicación. En la maestría actual sigo aprendiendo a escribir el castellano, sabiendo que la lengua es un instrumento de poder político que permite establecer relaciones de poder. 
Por todo ello concluyo mencionando que el aprendizaje de la escritura del castellano es un trauma que sobrepasa la institución escuela. Quizá hubiese sido distinto si se hubiesen adoptado otras políticas educativas y la metodología de la enseñanza del castellano, como segunda lengua, con un enfoque de producción de textos basados en la investigación y escritura de mi cultura. Al respecto de la enseñanza de la lengua propia o una segunda lengua, es importante tomar en cuenta la enseñanza de la oralidad, aquello que da vitalidad al uso de la lengua como mecanismo de poder; al mismo tiempo, ayude a desarrollar lengua y pensamiento.

\section{Conclusiones}

Marten Brienen (2005), enfatiza dos interpretaciones en cuanto al papel protagónico de las escuelas en la historia de la nación boliviana, las cuales se definen en términos de "resistencia" o de "expansionismo", donde las escuelas han sido entes de estrategia estatal para destruir la cultura indígena y reemplazarla con la visión de modernidad o, al contrario, como parte de una estrategia indígena de autopreservación cultural y de resistencia al expansionismo. El mismo Brienen parafraseando a Vitaliano Soria se refiere:

Ha afirmado elocuentemente la naturaleza de doble cara de la educación indígena, al sostener que mientras el estado buscó "eliminar la organización de los ayllus y liquidar la cultura nativa" con su ayuda de su programa educativo, las comunidades indígenas que enfrentaron esta estrategia criolla "buscaron en la escuela una estrategia de defensa de su propio proyecto de sociedad que se basaba en el fortalecimiento de sus ancestrales formas de organización socio-económica" (Brienen, 2005)

A pesar de los notables esfuerzos realizados por homogeneizar mediante la enseñanza antes que el aprendizaje "hegemonía institucionalizada en la escuela", la lengua aymara nos permitió plantear nuestro propio proyecto político, con base en la filosofía, la historia colonial y la cultura propia. Es así que algunos conservamos ese propósito de aprender el castellano en la escuela para "recuperar las tierras y los derechos usurpados durante la colonia". En la actualidad, los aymaras nos encaminamos hacia la restitución de los ayllus y con ella el poder político, social y económico. Una de las instituciones bien establecidas es el Consejo Nacional de Ayllus y Markas del Qullana Suyu (CONAMAQ) que es un consejo de gobierno indígena.

Por otro lado, la misma herramienta de la escritura y la misma preparación de los profesionales occidentales, nos han ayudado a des- 
cubrirnos que somos diferentes, con valores y modos de vida distintos, formas de registro y comunicación variada, valores morales y espiritualidad que sustentan nuestra propia existencia de ser aymaras. Si bien hay indígenas que están atrapados en la dominación epistémica, religiosa o económica, existimos también indígenas que utilizamos esas formas de pensamiento como formas de resistencia para la construcción de un proyecto político donde lo educativo llega a ser un instrumento de liberación y construcción de una sociedad basada en la diferencia o en las relaciones interculturales centradas no solo en el respeto o el reconocimiento, sino en el ejercicio de los derechos usurpados durante la colonia.

$\mathrm{Al}$ respecto. Esteban Ticona dice:

La revolución de 1952 y la Reforma Agraria de 1953 han abierto las puertas para una interacción cultural entre indios y no indios. La apertura masiva a la educación, pese a sus contenidos homogeneizadores, ha posibilitado que los propios indígenas y campesinos, a través de sus organizaciones, planteen la discusión de la Interculturalidad en sus diferentes manifestaciones". (Esteban Ticona en Memoria, política y antropología en los andes bolivianos 2005a)

Finalmente, en la enseñanza de la lengua, ahora, se reconoce la importancia del desarrollo de la oralidad antes que la escritura de una lengua. Biondi y Zapata (2006) sostienen que un texto "es el pre-texto para reconstruir lo imaginario de, lo cual es texto es residuo, re-presentar el original de que es base". Asimismo, se sabe que el hablante escribe una lengua de acuerdo a como habla; si tiene mayor riqueza de expresión tendrá mayores posibilidades de producir textos escritos, lo que quiere decir "la lengua hace al pensamiento y el pensamiento a la lengua", ambas son competencias complementarias para desarrollar una buena comunicación.

En la enseñanza actual, se tiene en boga el enfoque comunicativo textual y el paradigma constructivista desde la implementación de la Reforma Educativa. En ella, la atención se centra en el aprendizaje del alumno antes que en la enseñanza y desarrollaron el uso de estrategias didácticas par la enseñanza de segundas lenguas; asimismo, se considera el interés del aprendizaje de una lengua como un medio o sistema de comunicación antes que fin en sí mismo. Pese a conocerse técnicas diversas en la enseñanza de segundas lenguas aun existen vacios para desarrollar una educación bilingüe con características de mantenimiento y desarrollo de la lengua indígena especialmente la enseñanza de la lengua como instrumento político. Para ello es importante considerar la educación más allá de la institucionalidad de la escuela. Nos falta mucho por realizar prácticas educativas diferentes e investigaciones respecto a la enseñanza de una segunda lengua o lengua extranjera.

234 Gloria Huanca CALLISAYA. Escritura en castellano: um trauma más... 


\section{Algo de mí}

Mi nombre es Gloria Huanca Callisaya. Nací en Villa Remedios, Marka Viacha, provincia Ingavi del departamento de La Paz, Bolivia. Soy de la nación aymara, del territorio Jach'a Suyu Paka Jaqi, parcialidad Urqu Suyu. Las lenguas que hablo y escribo son el aymara y el castellano.

Tengo la formación de: Maestra Normalista, para ello estudie en el Instituto Normal Superior "Simón Bolívar" (La Paz) y la Licenciatura en Asesoría Pedagógica, la realicé en la Universidad Católica Boliviana "San Pablo" (UCB). Entre los cursos de Post-Grado, realicé un Diplomado en "Gerencia de Desarrollo de Proyectos en Salud" en las Maestrías para el Desarrollo de la UCB; una maestría en "Educación Superior" realizada en la Escuela Militar de Ingeniería (egresada) y soy estudiante regular de la quinta versión de la "Maestría en Educación Intercultural Bilingüe" dirigida por el Programa de Formación en Educación Intercultural Bilingüe para los Países Andinos (PROEIB-Andes) y la Universidad Mayor de San Simón (UMSS).

Desde hace varios años vengo trabando en el tema de educación intercultural bilingüe (EIB). Inicie como maestra implementando la EIB en una zona periurbana, luego fui parte del equipo de facilitadores en el Programa de Capacitación Docente en "Lectura y producción de textos en lengua Aymara" desarrollada por el PROEIB-Andes en convenio con el Ministerio de Educación, posteriormente fui técnico de EIB de la Región Aymara en la Dirección de Currículo del Área de Educación Alternativa (DGEA) del Ministerio de Educación. Actualmente soy facilitadora de un Centro de Educación Alternativa (educación de adultos) de nueva creación, al cual lo denominamos "Pablo Zárate Willka" ubicada en la ciudad de El Alto, en la que tratamos de implementar la educación bilingüe, desde cosmovisiones de cada cultura y como instrumento de reivindicación de lo nuestro.

\section{Notas}

${ }^{1}$ Según mi madre, los padres de ella migraron a otras ciudades, abandonando sus tierras, por no servir al patrón en la hacienda de Hilata Santa Trinidad - una de las comunidades de Viacha. Mi abuela contaba el sufrimiento que había pasado en la época de la hacienda y no quería que sus hijos/as pasaran la misma suerte. Frente a ello, lo mejor era escapar y ser libres aunque sea al costo de perder tierras. Entre los recorridos de migración estuvieron los departamentos de Oruro, Cochabamba hasta llegar a Santa Cruz. En el caso de mi padre quedó huérfano a temprana edad (siete 
años), los tíos de mi padre cegados por el interés quitaron las tierras ubicadas en la comunidad de Achica Arriba a mi abuela María Chinahuanca quien había quedado viuda; las hermanas y la madre de mi padre migraron de Achica a Villa Remedios (un pueblo aledaño a la comunidad) y mi padre empezó a viajar buscando trabajo y sobrevivencia. Cuando ya fue joven y casado regresó desde Santa Cruz a Villa Remedios con el propósito de recuperar las tierras que su padre había dejado. Según mi madre, la evangelización les permitióconocerse desde jóvenes hasta que llegaron a casarse. Actualmente mis padres viven en la comunidad Llajma Pampa, SubCentral Achica Arriba en y en una parte de las tierras que mi abuelo Frotacio Chinahuanca dejó para sus hijos/as (Encarnación, Cecilio y Eduarda Chinahuanca Chinahuanca).

${ }^{2}$ En las noches nos reuníamos en la casa de las ovejas para hablar sobre las preñadas, las doncellas, las crías, los machos castores y presas del próximo desollado. Mi madre con mucho cariño agarraba en sus faldas a las crías y les hablaba como se habla a las wawas recién nacidas. Las crías y sus madres como si entendieran nos jalaban de nuestras prendas, las crías dormían en nuestras faldas; al parecer, todas las ovejas estaban ya acostumbradas a recibirnos - en su casa - todas las noches a eso de las ocho a diez).

${ }^{3}$ Se dice así a los que son del departamento de Cochabamba.

${ }^{4} \mathrm{Mi}$ segundo hermanos e lleva solo un año y desde el primer curso de básico estudiamos juntos hasta primero de secundaria. Cuando tuvo la edad de 15 a 16 años y notó que podía tomar decisiones sobre su vida "desertó del colegió" presentándose al cuartel. De esta manera escapaba del colegio y de la imposición de estudiar por parte de mi padre.

${ }^{5}$ En este tipo de castigo los niños eran obligados a colocar los pies a la pared sujetando a todo su cuerpo en las manos que se colocaban en el piso. En este castigo los niños eran colgados por tiempos cortos o prologados, pero, como se quería escarmentar el profesor elegía la segunda opción.

\section{Referencias}

BIONDI, Juan; ZAPATA, Eduardo. La palabra permanente. Lima: Fondo Editorial del Congreso del Perú, 2006.

BRIENEN, Marten. Por qué Warisata no es lo que parece: la escuela-ayllu y el establecimiento del control estatal en la educación indígena. In: ROBINS, Nicolas A. (Ed.) Cambio y continuidad en Bolivia: etnicidad, cultura e identidad. La Paz: Asociación de Estudios Bolivianos/Plural, 2005.

TICONA, Esteban. Lecturas para la descolonizar: liberemos todos, Taqpachani qhispiyasipxañani. La Paz: Plural, 2005.

. Memoria, política y antropología en los andes bolivianos. Historia oral y saberes locales. La Paz: AGRUCO y Plural Editores, 2005a.

Recebido em 27 de fevereiro de 2008. Aprovado para publicação em 07 de março de 2008. 